\title{
Exposure to queer characters in Konigsberg's Openly Straight through social messaging
}

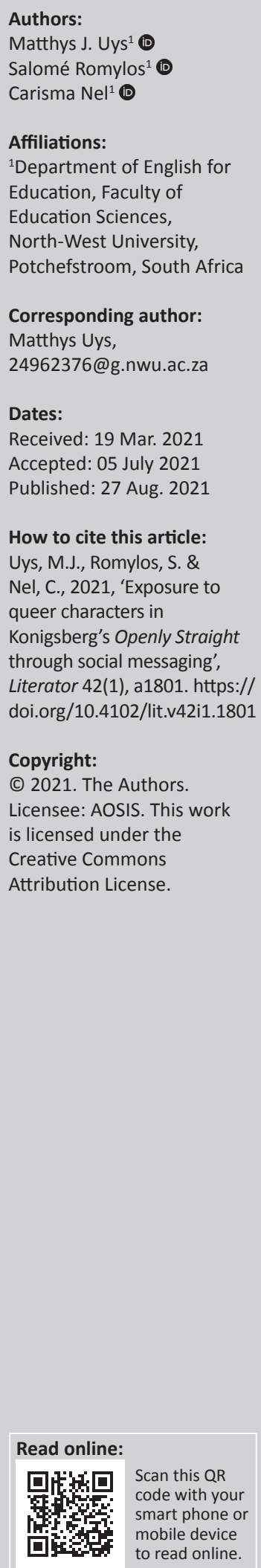

Research conducted by The Other Foundation has indicated that South Africans view the lives of queer individuals as lifestyle choice (34\%), illness $(12 \%)$, sin $(5.10 \%)$, results of these individuals' upbringing (3.80\%) and/or resulting from the influence of ancestral spirits (3.70\%). Advocacy and information about sexual orientation and sexual diversity through literary as characters may be instrumental in possibly changing negative perceptions of queer individuals. This article aims to show how a selected young adult queer novel, and the social messaging that emerges from the text, may be a potentially influential location for creating an awareness and better understanding of queer individuals. The aim of the investigation on which the article is based was to examine the possibility or viability of implementing critical literacy in secondary education systems in the language classroom as an opportunity to address social issues in heteronormative environments. The social messages found in queer texts may be used as entry points to fruitful discourse in language classroom environments. The study followed a qualitative approach with the use of critical hermeneutics as a strategy of inquiry and social constructivism as philosophical worldview. The queer text utilised was Openly Straight (2013) by Bill Konigsberg with the method of data generation being document analysis. The main findings were that queer texts should form part of the language classroom (as learners may read these texts critically and emphatically) and that Bill Konigsberg's Openly Straight contained social messages that can contribute to positive influences on queer- and heterosexual readers.

Keywords: critical literacy; social messaging; language classroom; classroom discourse; queer individuals; openly straight; Bill Konigsberg.

\section{Introduction}

Research has shown that South Africa is a queerphobic nation. This viewpoint may cause queer individuals to feel excluded as citizens of South Africa (Love Not Hate 2016; Nell \& Shapiro 2011:19; The Other Foundation 2016:3). Progressive Prudes (The Other Foundation 2016) highlights that there are a significant number of queer ${ }^{1}$ individuals in South Africa, and creating awareness and exposure, and improving the quality of these individuals' lives, should remain an area of research. The authors of this article therefore critically analysed and explored Konigsberg's (2013) Openly Straight and the social messaging that is prevalent in this queer text for the purpose of creating awareness and exposure to promote understanding of queer characters. This is achieved by applying critical literacy, and social messaging as a queer literary element, to a contemporary novel. A brief overview of The Other Foundation's Progressive Prudes publication (which entails the problem statement, rationale, research question, and aims and objectives of the study) is firstly given.

\section{Queerphobia in a heteronormative South Africa}

Perceptions of sexual orientation are often based on assumptions about people, which may result in treating others in unacceptable ways or marginalising them. The Other Foundation (2016:51) - a trust that promotes and progresses social inclusion and human rights of queer individuals in Southern Africa - states that South Africans have the following viewpoints concerning queer individuals: queerness is a lifestyle choice and not necessarily an accepted choice (34\%), an illness that should be cured $(12 \%)$, a sin $(5.10 \%)$, a result of a person's upbringing $(3.80 \%)$ and/or is influenced by ancestral spirits (3.70\%). The remaining $41.40 \%$ of the participants of this survey did not provide a viewpoint. The reason for providing these statistics is to show that there are

1.'Queer', according to the Cambridge English dictionary (2021), is defined as 'not fitting traditional ideas about gender or sexuality especially the idea that everyone is either male or female or that people should only have sexual relationships with the opposite sex'. Queer sexuality therefore challenges the inference that all individuals are heterosexual - the heteronormative norm. Additionally, queer may be used as an umbrella term for lesbian, gay, bisexual, transgender, intersex and additional gender identities (LGBTQ+) that differ from being 'straight'. It should also be noted that 'queer' is not used to denote a gender identity in this article. 
South Africans who have a queerphobic view when it comes to queer individuals, as queer identities do not comply with the heteronormative norm of heterosexuality. Additionally, the study entitled Hate Crimes against LGBT People in South Africa, conducted by a nationwide multi-partner initiative the Love Not Hate campaign (2016) - that addresses contextspecific queer violence, includes the experiences of queer individuals concerning the fear of discrimination, the fear of coming out, the fear of abuse and the fear of knowledge of queer individuals who have been murdered. The Other Foundation (2016:53), therefore, points out that these negative opinions and experiences of queer individuals can change through means of advocacy and information about sexual orientations.

Nell and Shapiro (2011:13, 15) and Blackburn and Miller (2017:1-3) clarify that secondary education systems are either opportunities or obstacles for young individuals. An opportunity is to provide queer learners with full participation (e.g. including queer-themed texts in the curriculum of the language classroom) in all educational programmes to eliminate queerphobia, prejudice and discrimination in school environments, and address the invisibility of queer identities in the curriculum. An obstacle to full participation is when young queer individuals are being attributed with characteristics (such as having a negative influence on others for being immoral and/or living in sin) they do not have when gender ideologies of heteronormative societies are reinforced in schools. In other words, in heteronormative schools, it may be believed that queersexual learners negatively influence heterosexual learners; however, this is not necessarily the case as queer learners are not essentially immoral or living in sin only because their sexual orientation differs from that of heterosexuals. Consequently, these young individuals may develop 'citizenship deficit' - a lack of belonging to the society (Eisner 1998:149; Jackson \& Boutte 2009:108, 112; Rosenblatt 1978; Zitlow 2000).

It is therefore crucial for any teacher to be aware of 'citizenship deficit' and to promote deeper experiences and knowledge for young queer individuals. Through this means, young queer individuals may engage positively with and in society, because these individuals are (or should be) fully qualified citizens (i.e. equal human rights and education, living normal lives and partaking in societal activities) of their countries (Eisner 1998:149; Jackson \& Boutte 2009:108, 112; Rosenblatt 1978; Zitlow 2000). As a result, teachers and the education systems should broaden the understanding of sexual diversity.

In South Africa, some of the principles that the National Curriculum Statement (NCS) Grades R-12 of the Curriculum and Assessment Policy Statement (CAPS) for Senior and Further Education and Training phases is based on are 'human rights, inclusivity, environmental and social justice' (Department of Basic Education 2011:5). These principles include sensitive issues of diversity (e.g. sexual orientation) to be included in the South African curriculum. The community, parents and guardians, schools, teachers and learners can all work together to normalise and mainstream sexual orientation and diversity by developing and implementing a critical literacy policy framework in the language classroom. Hence, social messaging as a queer literary element may be used to combat queerphobia and hegemonic heterosexism.

Television, parents, homes, schools, literature and teachers are sources that provide positive and negative messages for individuals. Literature, especially, provides opportunities for societal and cultural messages to be constructed, and the messages contained within challenge inequities and discrimination. Therefore, learners should be given opportunities to participate in classroom discussions concerning suitable messages (i.e. messages that are age appropriate and do not contain explicit language, sexual and violent content) in literature (Eisner 1998:149; Jackson \& Boutte 2009:108, 112; Rosenblatt 1978; Zitlow 2000). Such discussions may include diverse sexual orientations or gender identities.

Accordingly, the research question for this article, based on the underlying research problem, is as follows: What social messaging is prevalent in a contemporary queer novel that introduces learners to the positive and negative realities of fictional queer characters' experiences in a heteronormative society?

Societal and cultural messages can be constructed through critical literacy by readers (from sources such as literature) to contradict and supplement any messages they receive from school, home, the television and online platforms (i.e. Netflix, Showmax, Amazon, YouTube, Facebook and Twitter). The messages that are offered within young adult literature are critical for literacy achievement and the challenging of inequities and discrimination in the language classroom. Omission of texts with characters from diverse sexual orientations is an example of such discrimination. The queer literary element, social messaging, should be used to combat queerphobia and hegemonic heterosexism in language classrooms (Eisner 1998:149; Jackson \& Boutte 2009:108, 112; Rosenblatt 1978; Zitlow 2000).

This article aims to share the findings of the underlying investigation into how a selected young adult queer novel, Konigsberg's Openly Straight, for the purpose of determining the extent to which social messaging emerges from the text, may be a potentially influential location for creating an awareness and better understanding (of fictional queer characters' experiences in a heteronormative society) in the secondary education language classroom in general. This article also aims to establish or determine whether the implementation of critical literacy in secondary education systems in the language classroom could be seen or employed as an opportunity to address social issues in heteronormative environments.

Brief overviews of critical literacy and social messaging are provided next. This is followed by a short synopsis of Bill Konigsberg's Openly Straight and the application of critical 
literacy and social messaging to the novel. A discussion on classroom discourse of social messaging in queer literature in terms of criteria for selecting a queer-themed text and approaches to implement critical literacy in the language classroom - is given next. The article ends with some key conclusions and recommendations.

\section{Conceptual and theoretical framework}

Critical literacy allows a reader to collect, reflect on and interpret information gleaned from various genres (such as novels, poems, short stories and plays). Learners critically view biased texts as cultural, political and social forces and contexts, investigate primary ideas and materials that lead to viewpoints and values being intertwined with selfreflection and become involved and take social action based on their deliberation, synthesis, anticipation and examination of the change needed in topics such as power, social justice and equity (Glazier 2007:146). Following that, one asks questions (e.g. 'why?', 'who?', 'where?', 'when?' and 'how?') and critically reflects on the information gathered. Some information presented and accounted for as truthful facts are generally determined by individuals who have authority (McMillan \& O'Neil 2012:33-34), and these individuals benefit from those who believe these facts to be true. In other words, the authoritative individuals decide when something or someone is right or wrong, causing others to become gullible or ignorant because of a lack of reflection and questioning. Individuals may become more attentive to society when they are critically literate.

The reading of queer literature in the language classroom may result in learners reflecting and questioning the truthfulness of facts provided by those in authority, for example whether queer learners are immoral and living in sin.

Even though queer texts can be included in the language classroom, a critical literacy curriculum is overshadowed by hesitations and uncertainties experienced by teachers who do not have the necessary information to read literature critically (Lewison, Flint \& Van Sluys 2002:390). However, critical literacy instruction can be implemented by linking the class and the text to modern-day concerns and making real-life connections (Beck 2005:392, 397-398). Education and literary elements in texts - such as values, myths, images, messages, themes and characters - can expose or remind readers of the various kinds of lives that are possible. Young adult learners should read of smart, complex and interesting queer characters who reveal their gender identities to family, friends and acquaintances who are resistant, tolerant, accepting or celebrating. These queer characters, accordingly, also find love, overcome challenges and live full lives as human beings (who also have interests, thoughts and desires). As a result, positive exposure may promote awareness and understanding of these characters in heteronormative societies (Banks 2009:34-35), and especially the obstacles they often face.
Even though there are approaches that may aid teachers to implement a critical literacy curriculum in the English Home Language (EHL) or English First Additional Language (EFAL) classroom, which are discussed later in this article, there are also limitations.

Firstly, Samelius and Wågberg (2015:64) explain that it can be challenging to define queer identities and that there is not always a straightforward or simple answer for a complex question. The reason for this is that individuals perceive sexual orientations differently and that gender dichotomy men, women, gender-neutral and intersex - is not broad enough to describe the various real-world experiences and expressions of gender identity.

Secondly, Clark and Blackburn (2009:25) mention that discussing queer-themed texts from the point of view of a teacher may seem impossible to some. Limited or no training on queer literature and addressing social issues can become complex and daunting for teachers. Wright and Smith (2013:9) agree that teachers may be less prepared to successfully meet the learning needs (e.g. queer education in terms of finding one's identity) of queer learners.

Thirdly, Clark and Blackburn (2009:25-26) mention that the context of a school contributes to the limitation of queerthemed texts. The authority of the heterosexual individuals in a heteronormative society (who is generally the majority) surpasses the authority of queer individuals (who is generally the minority). Ignorant individuals, who view queer literature as inappropriate or unimaginable in the context of a language classroom, often contribute to queer literature being avoided.

These are but a few obstacles that may be encountered when advocating for the exposure of learners to texts about queer characters. These obstacles should, however, not deter efforts to introduce texts with diverse gender identities into the English HL and FAL classroom. The next section entails a discussion on how social messaging may be employed within a critical literacy framework.

\section{Social messaging Openly Straight (Bill Konigsberg 2013)2}

Openly Straight is introduced by Bill Konigsberg when he makes it known from the beginning that the main protagonist, Rafe Goldberg, does not want to be openly gay anymore, but rather wants a second chance at his heterosexuality, even if it means he needs to go back 'into the closet'. To achieve this, Rafe moves across the country to change schools. Even though his parents and friends celebrated his sexual diversity, he wants to experience a life free of labels.

At his new school, Natick, Rafe can socialise with all his peers as he has no intention of sharing his true sexual

2.Even though the novel in question is set in an American society, the focus of the article - social messaging - is universal. Thus, the novel can be included in the South article-social messaging - is universal. Thus, the novel can be included in the South
African context as learners can relate to the American setting with regard to social messaging. 
orientation with anyone. However, Rafe soon meets Ben and, not long after, their friendship grows and becomes more intimate. As Ben is heterosexual and Rafe secretly gay, complexities, conflictions, confusions and dishonesty occur. Nevertheless, during Rafe's journey, he finally knows what it means to celebrate his true sexuality. The social messaging, identified in Bill Konigsberg's Openly Straight, is acceptance, Gay-Straight Alliance, coming out, stereotypes and labels, queer knowledge and assumptions, bromance, love and perspectives on life.

The first social messaging that is discussed that occurs in Openly Straight is the 'acceptance of queer learners'.

\section{Acceptance of queer learners}

Rafe is soon informed by Mr Scarborough (a teacher) that he knows Rafe is gay and that Natick (his new school) has a Gay-Straight Alliance. Natick is not depicted as a homophobic school: 'the year before, they'd even had a former college football player who was gay come speak', and '... Natick was adjusting to the "new world order" where gay was okay'.

Even though Rangeview (back in Boulder), Rafe's previous school:

$[W]$ as an open and accepting school ... A safe place [...] And no one's head exploded ... And nobody got beaten up, or threatened, or insulted [...] It all went pretty great. (Konigsberg 2013:2-4)

Rafe still leaves the school to escape the spotlight that is on him for being openly gay. The positive message of supporting queer individuals is, nonetheless, supported by both schools. Being queer is still not celebrated but rather seen as tolerable or acceptable. Rafe explains that these viewpoints reflect something that should be kept to oneself: '... to help kids understand how hard it is for gay people when they are told, like, "It's okay if you're gay, just don't talk about it"' (Konigsberg 2013:41-42). The 'accepting' stage progresses towards the 'celebration' stage and regresses from the 'rejection' stage, as well as the 'tolerance' stage (since tolerance still entails disapproval to some extent), but Rafe explains that it is still problematic because queer individuals, generally, may only share their stories in Gay-Straight Alliances.

The next social messaging that occurs in Openly Straight is the 'Gay-Straight Alliance' at Rafe's high school, Natick.

\section{Gay-straight alliance}

At the end of Konigsberg's novel, Rafe joins Natick's GayStraight Alliance when he celebrates being gay. Just as the group, Alcoholics Anonymous (AA), shares the problem of struggling with excessive alcohol intake, the Gay-Straight Alliance is depicted similarly to share a common problem of 'citizenship deficit'. A Gay-Straight Alliance provides the positive message of queer and heterosexual individuals aligning and learning from one another. These individuals may also speak from their hearts and express themselves. Himpe (2017) agrees that Gay-Straight Alliances provide the opportunity for many queer- and heterosexual learners a place to feel safe, regardless of how anyone identifies. Littlefield (2016:50) contributes by mentioning that Konigsberg shows how queer-and heterosexual individuals appropriately deal with queer sexuality. Porta et al. (2017) add that Gay-Straight Alliances provide opportunities for queer individuals for leadership and to form part of a community, to have a sense of support, emotional connection and belonging. Additionally, these alliances are a gateway to other outside resources (e.g. informal social location and supportive adults) that do not form part of the Gay-Straight Alliance. Generally, those individuals (such as Rafe, Mickey and Jeff who are gay characters in Openly Straight) attending and sharing openly can do so without expecting any judgement, for example gay characters who hide their sexual orientation in heteronormative environments to avoid standing out and possible prejudice and abuse:

'I [Rafe] just wanted to be me for a bit. Without my sexuality being on display, you know?' [...] 'I get that,' Jeff said. 'Go under the radar a little. I'm like that sometimes too. Like, why do we have to march in parades and all that stuff?' 'But if we don't march in parades, people don't see us,' Mickey said [...] 'What do you mean?' Jeff said. 'People aren't going to stop seeing gays because they don't march in some stupid parade. Straight people don't march in a parade'. (Konigsberg 2013:307-308)

Jeff understands why Rafe hides his sexuality as he sometimes wants to do the same. The conversation between Rafe and Jeff touches on assumptions: one discussion centres on the fact that queer individuals do not have to march in parades in order for their voices to be heard, but may make use of other ways, such as making films or writing books. In addition, heterosexual individuals may also march in parades (as this is not only reserved for queer individuals) as the focus should be on the parade's purpose (e.g. the power of women, stop drug testing on animals and stop farm murders). Openly Straight, thus, shows how a Gay-Straight Alliance is used for individuals to share and critically discuss with one another by forming an alliance, and highlights the underlying awareness of different expectations for heterosexual and gay individuals.

'Coming out' is another social message that occurs in Openly Straight.

\section{Coming out}

When Rafe starts attending Natick's Gay-Straight Alliance, Mickey, one of the members, states that heterosexual individuals do not, like queer individuals, have to come out of the closet - in hegemonic heteronormative societies, it is assumed that all individuals are heterosexual. Micky then asks Jeff comically, as if telling a 'knock-knock joke', 'What do you call it when a straight person comes out? ... A conversation' (Konigsberg 2013:307-308). Accordingly, heterosexual individuals, because of heteronormativity, 
do not experience such fears as queer individuals have to come out of the closet as it is assumed that it is normal to be heterosexual. Queer individuals, on the other hand, need to 'come out' of the closet in order not to 'live a lie'. In summary, Connell (1992:744) states that queer individuals usually experience six stages when coming out: (1) prehistory, (2) preparation, (3) contact, (4) acknowledgement, (5) immersion and (6) consolidation. In other words, the queer individuals become aware that there is a difference in their gender identities when compared to heteronormativity, and eventually act on it. For example, a gay individual becomes more acquainted with his sexuality, notices boys or men more and seeks an intimate relationship. There seems to be quite a process when queer individuals come out, linking to the fear Mickey makes reference to in his statement. Mickey further explains that:

[S] traight people don't have to think, every time they talk, about whether they are coming out. We do. That might be hard, but that's also why we have to come out. If we don't, it's pretty much impossible to have a conversation about anything beyond the weather without lying. (Konigsberg 2013:307-308)

The social message expressed here is that queer individuals, who are still in the closet, at some point need to lie as they are not open about their sexual orientations. When one is living a lie, one has to constantly be aware of what one says to whom in order to avoid exposing oneself by mistake. It can therefore be seen that heterosexual individuals have it easier as they do not have to come out of the nongay closet; they also do not have to be aware of what they are saying all of the time, because heterosexuality is already assumed, exposed and celebrated in predominantly heteronormative societies. In retrospect, Fuss (1991), as cited by Namaste (1994), explains that the application of gender identities in medical and legal terms engendered a paradox:

[A]lthough the adoption of homosexual identity allowed for the guarantee of civil rights, it brought with it the notion of the closet - that is, the idea that some people are 'visible' about their sexualities while others remain silent. (pp. 224, 226)

Accordingly, a queer individual can come out, but emphasis has been placed on the 'naturalness' of heterosexuality, and the inference that there are queer individuals who are not yet out. The individuals who are not out can thus experience more fear because they intentionally keep an important aspect of their lives secret.

The next social messaging of Openly Straight that is discussed is 'stereotypes and labels'.

\section{Stereotypes and labels}

Stereotypes and labels are two types of judgement that occur in Openly Straight. Rafe, for example, makes several statements on judgement, 'Who the hell were they to judge me?' and '... who was I to label?' (Konigsberg 2013:21-22). Rafe, though, knows that he judges other individuals, too. Stereotypes can also be seen as a form of judgement. This is evident when Albie says to Rafe, 'You're a jock who screams like a girl' (Konigsberg 2013:82). Hence, Konigsberg contributes to the creation of the 'jock' stereotype. Jocks are generally sportsmen who are unafraid and manly, and who do not scream like girls. At the same time, Albie does not know of Rafe's hidden gay identity. Furthermore, not only is Albie insulting Rafe and acknowledging the jock stereotype, but he is also insulting and mocking the female gender.

When Rafe was still at Rangeview (during Halloween) and dressed up like a rocker's chick from the 80s, he was labelled a drag queen. However, two football boys were considered funny when they also dressed as women: 'When the two football guys wore women's clothing, [Rafe's] pretty sure nobody called them drag queens' (Konigsberg 2013:152). Rafe reflects that those individuals that labelled him saw his 'outfit like a political statement, or proof that deep inside [he] really wanted to be a woman' (Konigsberg 2013:152). It implies that heterosexual individuals are able to accept gays when they act like women or are in drag. Consequently, ignorance results in queer individuals being placed in one camp when there are differences amongst gays, lesbians, bisexuals, transgenders, etc. The second aspect here is that heterosexual individuals are not judged harshly compared to queer individuals in similar situations. Rafe is not seen as comical, but is judged instead.

Even Rafe's father, Gavin, stereotypes when he says:

[Y]ou're no fag, okay? You don't owe those idiots any explanation about who you are. They'd be lucky to be half the man you are, Rafe. Okay? We love you. Don't fight those idiots. (Konigsberg 2013:207)

Gavin calls the boys 'idiots' who verbally abused his son. The word 'fag' is used to insult a gay and is therefore a derogatory term. The insult 'idiot' would refer to someone lacking common intelligence. When Rafe is labelled a 'fag', the boys are labelled 'idiots'. Carlton, another Gay-Straight Alliance Natick member, states, 'I hate labels ... I'm just me' (Konigsberg 2013:307-308). Konigsberg uses Carlton to portray the positive message that no individual, whether queer or heterosexual, wants to be stereotyped and labelled, because labels only emphasise a single aspect of the label holder (Littlefield 2016:36).

Another social message, 'queer knowledge and assumptions', occurs in Openly Straight.

\section{Queer knowledge and assumptions}

The following quotation shows the words of Gavin (Rafe's father) and emphasises that no individual understands everything and that making assumptions can have negative messages: '[ $t]$ he universe is infinite'. In my [Rafe] dad's language, that means, I'm just a guy. What do I know? (Konigsberg 2013:6). Fortunately, queer individuals may provide insight into their lives; they can create understanding and awareness. The following extract shows 
how queer individuals can be confronted by the ignorance of heterosexual individuals:

... this ... girl from school ... had chatted me [Rafe] up on Facebook. We talked about normal things..., and then she was like, 'If you let me, I could switch you'. I was like, 'Switch me?' She said, 'Yeah. It's cool you're gay. But I could make you bi'. (Konigsberg 2013:88)

Konigsberg emphasises the message here that queer individuals' identities are not something, like fashion, that can change. For example, Rafe will not become heterosexual or bisexual when he kisses a girl. This is also a stereotypical assumption made by many heterosexual individuals that a woman can 'correct' a gay man or a man can 'correct' a lesbian. However, heterosexual individuals are not entirely to be blamed for lacking knowledge of queer individuals. This is why queer education, yet again, is necessary, because readers conclude that all individuals, each in their own right, are human beings, just like Rafe does when he says, 'People are people' (Konigsberg 2013:161)

A 'bromance' is also considered as a social message in Openly Straight.

\section{Bromance}

Konigsberg (2013:179) depicts through Rafe and Ben a 'bromance', which refers to a brotherly connection between two boys or men. Konigsberg makes it clear how men view a bromance with criticism and fear. In a heteronormative environment, two men - whether both are queer, both are heterosexual, or the one is queer and the other heterosexual - who have a bromance, are frowned upon out of fear that the relevant parties might actually be in a sexual relationship. In the following quotation, Ben and Rafe explain what a bromance is:

'That connection. It's hard to replace. I [Ben] can't tell you how many times last spring I'd hang out all night with Bryce, talking about Cindy. It was like, that friendship, that closeness with Bryce. That was my replacement' [...] 'Yeah, I [Rafe] feel in a lot of ways closer to you than I ever did to Claire Olivia'. (Konigsberg 2013:179)

A bromance does not necessarily entail men having sexual relations. It refers to individuals who can share personal issues or secrets. It is, rather, a connection that is stronger than being simply friends. For example, two men kissing, for whatever the reason may be (greeting each other, congratulating each other, etc.), does not necessarily mean that they are gay, but that they have a bromance (Ralph \& Roberts 2020:98). However, as male intimacy, like a bromance, is not considered manly, it is mostly frowned upon in a heteronormative society through the means of homohysteria (Miles 2015). Hanish and Fabes (2014) elaborate that boys are more dominant, more active and more aggressive when they play with the same sex, whereas girls are seen as more prosocial and compliant. As a result, bromances are frowned upon as this connection is not dominant, active and aggressive, but prosocial and compliant - something rather reserved for girls.
The last social messaging that is examined of Openly Straight in this article is 'love and perspectives on life'.

\section{Love and perspectives on life}

Konigsberg shows in his novel that a young reader can be positively influenced through love and various perspectives on life. An example is how Rafe's mother, Opal, reacts when he confides in her about his relationship with Ben:

[T] here are so many different kinds of relationships out there, sweetie. The thing that makes one okay and another not, is whether it comes from a place of love. Nothing that comes from love could ever be wrong. (Konigsberg 2013:254)

Opal does not see queersexuality as a sinful act when love is involved. Griffin and Ouellett (2003) mention that sin is universal, and any situation can be made sinful by any individual. Opal's view focuses on the love individuals share with each other. To appreciate love is something anyone can do, regardless if they approve or disapprove of queer sexuality.

A second example is noticeable when Bryce, the only black student at Natick, becomes depressed for being different when compared to his peers. Littlefield (2016:42) explains that individuals look through various lenses at the world:

Bryce said it's like lenses that you see the world through. They shift your perspective on everything you see. They create what's real for you, and unlike glasses, you can never take them off and see what normal is to other people, you know? Bryce had two [being sensitive and black], and he said it was hard to relate to some of the students here, who seem to have none. (Konigsberg 2013:220)

According to Bryce, distorted or negative lenses generally accompany individuals who are ignorant. For example, if a heterosexual individual looks with a queerphobic lens at queer individuals, it can lead to rejection or mere tolerance of the individuals in question. However, should the same heterosexual individual look at queer individuals through a lens of love, the focus will not be on the fact that the queer individuals are in relationships, but on the love these individuals share. Hence, Konigsberg shows that the lenses used will determine whether the world is looked at positively or negatively.

As the social messaging that occurs in Openly Straight has now been examined, two classroom discourses of social messaging in queer literature - the criteria for selecting a queer text and three approaches to implement critical literacy in the language classroom - are discussed next.

\section{Classroom discourse of social messaging in queer literature}

The possible (but subject to change) criteria (Uys 2020:63, 204) for the selection of 'high-quality' (Blackburn \& Miller 2017:5) queer-themed texts and documents for the EHL and EFAL language classroom are that teachers should identify whether the text is queer-themed and what queer point of view it 
entails. Furthermore, to make sure that the target audience for the text is young adults, teachers should detect whether the majority of the queer characters are in fact young adults. Following this, teachers should make sure that the text is age appropriate and entertaining for the language classroom, as certain young adult literature may contain sexual or too violent images, which can lead to learners becoming uncomfortable and sensitive. Importantly, teachers should recognise whether a prominent heteronormative society issue (e.g. psychology - risk decisions; coming of age, socioeconomic issues and fanaticism) is addressed or explored in the text that is relevant to the perspectives of queer individuals and also promotes multiple opportunities for all learners to engage with the text. When the suggested criteria (Uys 2020:63, 204) are applied to Bill Konigsberg's Openly Straight, it is determined that the text is queer-themed and entails a gay point of view. Rafe, Ben, Albie, Toby, Bryce, Claire Olivia, Steve, Zack, Jeff, Mickey, etc., are all young adult characters, whilst the minority of the characters - for example Gavin, Opal and Mr Scarborough - are adults. There is no violent or sexual content that is inappropriate at the level of secondary education systems, and the prominent theme, 'the search for one's identity', is addressed and explored.

Following the suggested criteria for selecting a queer-themed text (Uys 2020:63, 204), Behrman (2006:492-494) provides the following three approaches for a classroom environment to implement a critical literacy curriculum: supplementary text reading, multiple text reading and resistant perspective reading. These approaches are relevant to primary, secondary and tertiary education systems, but for the purpose of this article will only be applied to secondary education systems, as Openly Straight by Bill Konigsberg is appropriate to secondary education systems.

Firstly, supplementary text reading entails the teacher to supplement the traditionally chosen texts with other (non-) fiction, film and/or popular culture works. Where canonical or traditional texts possibly avoid or skim over social queer issues (e.g. the search for identity, prejudice and abuse, and religious zealotry), supplementary texts (such as queer literature) allow learners to address and critically discuss these issues. For example, in the secondary education system of South Africa, one of the Grade 12 English Home Language literature set works is The Picture of Dorian Gray (written by Oscar Wilde in 1890). Correspondingly, one of the Grade 12 EFAL literary set works is Cry, the Beloved Country (written by Alan Paton in 1948) (South Africa Department of Basic Education 2016). The Picture of Dorian Gray focuses on a fashionable young man who sells his soul for beauty and eternal youth, and the consequences that follow because of corruptive influences and moral integration (Goodreads 2020b). Cry, the Beloved Country tells the story of Stephen Kumalo (the Zulu pastor), Absalom (his son), and James Jarvis and the murder of Arthur (James's son), who live in South Africa that is marred by racial injustices (Goodreads 2020a). Supplementary text reading can be implemented by substituting The Picture of Dorian
Gray or Cry, the Beloved Country with Bill Konigsberg's Openly Straight, but this may not be so easy as panels decide on the prescribed literature for the EHL and EFAL NSC. Nonetheless, the supplementation of canonical texts will allow learners to have fruitful discussions on the social messages of acceptance, Gay-Straight Alliance, coming out, stereotypes and labels, queer knowledge and assumptions, bromance, love and perspectives on life that emanate in Openly Straight.

Secondly, critical literacy can be developed through multiple text reading on the same topic. Learners can contemplate the how, when, who, why and where of the multiple texts that are consulted, recognising that these fictional texts are not in any definite sense true, but authorportrayed interpretations of the topic. For example, Brent Hartinger's 2004 queer novel, Geography Club, addresses prejudice and abuse from gay, lesbian and bisexual characters' perspectives, whereas Jeanette Winterson's 1985 queer text, Oranges are not the Only Fruit, addresses religious zealotry from a lesbian perspective. Should learners read these three texts (including Bill Konigsberg's Openly Straight) in secondary education systems, they are reading multiple texts on the same topic (which is queersexuality), and will contemplate the authors' reasons for writing the texts. The learners will also be exposed to various themes (prejudice and abuse, religious zealotry and the search for identity) that are relevant to the topic.

Lastly, resistant perspective reading in the classroom environment emphasises the reader's values and the author's stance, forming an awareness that is conscious of text interpretation and the effect thereof. Subsequently, learners undertake unfamiliar or new identities, read from a different frame of reference than normally used and evaluate and accept a statement or argument from the point of view of the author. Heterosexual learners in secondary education systems, for example, may read a queer-themed text, such as Openly Straight by Bill Konigsberg, in the language classroom that is told from the point of view of a fictional queer character (Rafe - gay), and try to experience searching for their identities through the eyes of Rafe. Even though heterosexual learners can be resistant to reading a queer-themed text, they will become more aware of social issues that are relevant to queer individuals (such as the acceptance or celebration of various sexual orientations).

Behrman (2006:497) concludes that the above-mentioned approaches give a text meaning instead of containing meaning, and that texts do not only entail fictional stories, but provide meaning for the greater good.

Queerphobia and hegemonic heterosexism in all schools can be challenged through critical literacy as this develops increased awareness and understanding. Possible recommendations for addressing the problem are that teachers can implement supplementary text reading, multiple text reading and 
resistant perspective reading as approaches to implement a critical literacy curriculum. Furthermore, queer texts should form part of the language classroom; learners will be encouraged to read these texts critically and emphatically using the critical literacy lens, and as a result, they gain positive exposure to fictional queer characters. Even though the incorporation of queer-themed texts in a school curriculum will garner resistance, it is still possible when teachers receive the necessary guidance and knowledge of critical literacy - for example guidelines (i.e. literary analyses of queer texts and lesson planning) - for secondary EHL and EFAL teachers can be given through education systems. The incorporation of such texts in a curriculum will provide opportunities to queer learners to identify with characters who resemble them and have the same aspirations, thoughts, feelings and fears.

\section{Conclusion}

In conclusion, the main findings of the analysis of the book were that queer texts should form part of the language classroom as learners may read these texts critically and emphatically, which results in receiving exposure to fictional queer characters. Bill Konigsberg's Openly Straight contained social messages that could contribute to positive influences on queer- and heterosexual readers, and supplementary text reading, multiple text reading and resistant perspective reading as discourse approaches, to implement critical literacy in the language classroom, give a text meaning instead of containing meaning. However, this negative viewpoint and its consequence may be overcome by exposing individuals to queer-themed texts by implementing critical literacy in the language classroom and examining the social messaging that emanates from the queer text.

\section{Acknowledgements}

Prof. J.L. van der Walt (North-West University) assisted in writing the article.

\section{Competing interests}

The authors have declared that no competing interest exists.

\section{Authors' contributions}

M.J.U. - formal analysis; writing - original draft. S.R. supervision - writing, reviewing and editing. C.N. supervision; writing, reviewing and editing.

\section{Ethical considerations}

This article followed all ethical standards for a research without direct contact with human or animal subjects.

\section{Funding information}

This research received no specific grant from any funding agency in the public, commercial or not-for-profit sectors.

\section{Data availability}

The authors confirm that the data supporting the findings of this study are available within the article. The references may be consulted to validate the information provided.

\section{Disclaimer}

The authors confirm that the submitted article is their own and not an official position of the institution.

\section{References}

Banks, W.P., 2009, 'Literacy, sexuality, and the value(s) of queer young adult literature', The English Journal 98(4), 33-36.

Beck, A.S., 2005, 'A place for critical literacy', Journal of Adolescent \& Adult Literacy 48(5), 392-400. https://doi.org/10.1598/JAAL.48.5.3

Behrman, E.H., 2006, 'Teaching about language, power, and text: A review of classroom practices that support critical literacy', Journal of Adolescent \& Adult Literacy 49(6), 490-498. https://doi.org/10.1598/JAAL.49.6.4

Blackburn, M. \& Miller, M.C., 2017, Equity by design: Teaching LGBTQ-themed literature in English language arts classrooms, Midwest \& Plains Equity Assistance Center, viewed 20 January 2020, from http://glec.education.iupui.edu/ImagesBriefs/2017_07_24 TeachingLGBTQ_Brief.pdf.

Cambridge English Dictionary, 2021, Queer, viewed 12 July 2021, from https:// dictionary.cambridge.org/dictionary/english/queer.

Clark, C.T. \& Blackburn, M.V., 2009, 'Reading LGBT-themed literature with young people: What's possible?', The English Journal 98(4), 25-32. https://doi.org/10.10 80/00098655.2017.1366183

Connell, R.W., 1992, 'A very straight gay: Masculinity, homosexual experience, and the dynamics of gender', American Sociological Review 57(6), 735-751. https://doi. org/10.2307/2096120

Eisner, E., 1998, The kind of schools we need: Personal essays, Heinemann, Portsmouth, $\mathrm{NH}$.

Glazier, J.A., 2007, 'Teaching story: Anti-oppressive pedagogy and curriculum in secondary English methods: Focusing on critical literacy', Counterpoints 315, 141-148.

Goodreads, 2020a, Cry, the beloved country, viewed 19 April 2020, from https://www. goodreads.com/book/show/6150.Cry_the_Beloved_Country?ac=1\&from_search $=$ true \&qid=SAhQqyTRUN\&rank=1.

Goodreads, 2020b, The picture of Dorian Gray, viewed 19 April 2020, from https:// www.goodreads.com/book/show/5297. The Picture of Dorian Gray?from wWW.goodreads.com/book/show/5297.The Picture

Griffin, P. \& Ouellett, M., 2010, 'From silence to safety and beyond: Historical trends in addressing lesbian, gay, bisexual, and transgender issues in k-12 schools', Equality \& Excellence in Education 36(2), 106-114. https://doi.org/10.1080/10665680303508

Hanish, L.D. \& Fabes, R.A., 2014, 'Peer socialization of gender in young boys and girls. Encyclopedia on Early Childhood', Gender: Early Socialization, viewed 20 April 2020 from http://www.child-encyclopedia.com/sites/default/files/textes-experts/ en/2492/peer-socialization-of-gender-in-young-boys-and-girls.pdf/.

Himpe, J., 2017, 'So, what exactly is a gay straight alliance?', Global News, viewed 03 November 2019, from https://globalnews.ca/news/3841162/so-what-exactlyis-a-gay-straight-alliance/.

Jackson, T.O. \& Boutte, G.S., 2009, 'Liberation literature: Positive cultural messages in children's and young adult literature at freedom schools', Language Arts 87(2) children's
108-116.

Konigsberg, B., 2013, Openly straight, Levine Books, New York, NY.

Lewison, M., Flint, A.S. \& Van Sluys, K., 2002, 'Taking on critical literacy: The journey of newcomers and novices', Language Arts 79(5), 382-392.

Littlefield, J., 2016, 'Understanding homosexual identities in modern young adult literature: An analysis of rainbow boys, openly straight, and boy meets boy', MA dissertation, East Carolina University.

Love Not Hate, 2016, Hate crimes against lesbian, gay, bisexual and transgender (LGBT) people in South Africa, viewed 01 March 2019, from https:///C:/Users/ cumla/Downloads/Hate $\% 20$ Crimes $\% 20$ Against $\% 20$ LGBT $\% 2$ People $\% 20$ in $\% 20$ South $\% 20$ Africa $\% 2021 \% 20$ November $\% 202016 \% 20$ Web.pdf.

McMillan, L. \& O'Neil, M.A., 2012, 'Literacy and social equity', Counterpoints 406, 30-44.

Miles, P., 2015, Bromance, viewed 05 February 2020, from https://www.boldgrace. org/articles/bromance.html.

Namaste, K., 1994, 'The politics of inside/out: Queer theory, poststructuralism, and a sociological approach to sexuality', Sociological Theory 12(2), 220-231. https:// doi.org/10.2307/201866

Nell, M. \& Shapiro, J., 2011, Out of the box: Queer youth in South Africa today, The Atlantic Philanthropies, New York, NY

Porta, C., Singer, E., Mehus, C.J., Gower, A.L., Saewyc, E., Fredkove, W., 2017, 'LGBTQ youth's views on gay-straight alliances: Building community, providing gateways, and representing safety and support', J Sch Health 87(7), 489-497. https://doi. org/10.1111/josh.12517

Ralph, B. \& Roberts, S., 2020, 'One small step for man: Change and continuity in perceptions and enactments of homosocial intimacy among young Australian men' Men and Masculinities 23(1), 83-103. https://doi.org/10.1177/1097184X18777776 
Rosenblatt, L., 1978, The reader, the text, the poem: The transactional theory of the literary work, Southern Illinois University Press, Carbondale, IL.

Samelius, L. \& Wågberg, E., 2005, Sexual orientation and gender identity issues in development, Swedish International Development Cooperation Agency, Stockholm.

South Africa Department of Basic Education, 2011, Curriculum and assessment policy statement. English Home Language. Grades 7-9, Government Printers, Pretoria.

South Africa Department of Basic Education, 2016, Circular E39 of 2016 Implementation of Grade 12 National Senior Certificate (NSC) literature set-works for all official languages, Government Printers, Pretoria
The Other Foundation, 2016, Progressive prudes: A survey of attitudes towards homosexuality \& gender non-conformity in South Africa, The Other Foundation, Johannesburg.

Uys, M.J., 2020, A literary analysis of queer texts: guidelines for senior and further education and training English language teachers, Diss, North-West University, Potchefstroom.

Wright, T.E. \& Smith, N., 2013, 'Bullying of LGBT youth and school climate for LGBT teachers', GEMS 6(1), 1-12. https://doi.org/10.5561/5010

Zitlow, C.S., 2000, 'Sound and pictures in words: Images in literature for young adult', ALAN 27(2), 20-26. https://doi.org/10.21061/alan.v27i2.a.6 